\title{
Deformation Characteristics of Ultrahigh-Strength Concrete under Unrestrained and Restrained States
}

\author{
Joo-Ha Lee, ${ }^{1}$ Kwang-Mo Lim, ${ }^{1}$ Doo-Yeol Yoo, ${ }^{2}$ and Nam-Hyoung Lim $^{3}$ \\ ${ }^{1}$ Department of Civil Engineering, The University of Suwon, 17 Wauan-gil, Bongdam-eup, Hwaseong-si, \\ Gyeonggi-do 18323, Republic of Korea \\ ${ }^{2}$ Department of Architectural Engineering, Hanyang University, 222 Wangsimni-ro, Seongdong-gu, Seoul 04763, Republic of Korea \\ ${ }^{3}$ Department of Civil Engineering, Chungnam National University, 99 Daehak-ro, Yuseong-gu, Daejeon 34134, Republic of Korea \\ Correspondence should be addressed to Nam-Hyoung Lim; nhrim@cnu.ac.kr
}

Received 6 March 2017; Accepted 14 May 2017; Published 5 July 2017

Academic Editor: Xiao-Yong Wang

Copyright (C) 2017 Joo-Ha Lee et al. This is an open access article distributed under the Creative Commons Attribution License, which permits unrestricted use, distribution, and reproduction in any medium, provided the original work is properly cited.

\begin{abstract}
As structures like skyscrapers and long-span bridges become larger, the demand for higher strength of concrete is increasing. However, research on ultrahigh-strength concrete (UHSC) is still in its infancy. In particular, UHSC is known to have a considerably higher level of autogenous shrinkage than normal strength concrete (NSC), and the possibility of cracking at an early age is very high. Therefore, in this study, shrinkage and cracking behavior of high-strength concrete (HSC), very-high-strength concrete (VHSC), and UHSC were evaluated through unrestrained shrinkage test and restrained shrinkage test (ring test). The primary experimental variables are the compressive strength level according to the water-to-binder ratio (W/B), fly ash content, and concrete specimen thickness. The experimental results demonstrated that the drying shrinkage decreased as the W/B ratio and the fly ash replacement ratio increased, and the restraint cracks appeared to be the earliest and most brittle in the UHSC with the smallest W/B. Increased concrete thickness and incorporation of fly ash were observed to inhibit crack initiation effectively.
\end{abstract}

\section{Introduction}

Volume reduction of concrete by shrinkage is constrained by factors such as rebar, coarse aggregate, and formwork. Constrained stresses from shrinkage cause initial cracking, which deteriorates the durability of the structure and causes sudden destruction of the structure at unexpected loads $[1,2]$. Shrinkage is generally divided into autogenous shrinkage and drying shrinkage. Autogenous shrinkage is not caused by external influences (load, moisture evaporation, temperature change, etc.) but rather by the self-desiccation phenomenon due to hydration reaction. Dry shrinkage occurs when the free water inside the concrete evaporates to the outside due to the difference in relative humidity. The main mechanisms of the shrinkage are (a) capillary tension due to moisture change, solid surface tension, and disjoining pressure, (b) chemical shrinkage, (c) thermal shrinkage, and (d) carbonation shrinkage [3].

Planar concrete structures such as bridge decks, road pavements, parking lots, and factory floors, which are applied with normal strength concrete (NSC), are subject to large shrinkage due to increased external exposed surface and free water, so cracks are likely to occur [4]. Furthermore, highstrength concrete (HSC) and ultrahigh-strength concrete (UHSC), which have been actively researched and developed because interest in high-rise buildings and long-span bridges has increased rapidly, have considerably higher autogenous shrinkage than NSC and have a high possibility of cracking at an early age [5-7].

Previous studies have shown that fly ash increases the long-term strength, durability, and workability of concrete and induces initial setting delay and shrinkage reduction by pozzolanic reaction [8]. In addition, the delay of the initial hydration reaction reduces the risk of cracking due to hydration heat and initial restraining stress.

The initial cracking behavior is influenced not only by the development rate and the amount of concrete shrinkage but also by the constraint, relaxation of stress, age, and shape of the structure [9]. Therefore, it is impossible to evaluate the strength development, the change of concrete stress, and 
TABLE 1: Mix proportions.

\begin{tabular}{|c|c|c|c|c|c|c|c|c|c|}
\hline \multirow{2}{*}{ Mix } & \multirow{2}{*}{$\mathrm{W} / \mathrm{B}$} & \multirow{2}{*}{ S/A (\%) } & \multicolumn{6}{|c|}{ Unit weight $(\mathrm{kg} / \mathrm{m} 3)$} & \multirow{2}{*}{ SP (\%) } \\
\hline & & & $\mathrm{W}$ & $\mathrm{C}$ & SF & FA & S & G & \\
\hline HSC & 0.30 & 41.0 & 171 & 580 & - & - & 666 & 973 & 0.8 \\
\hline VHSC & 0.25 & 41.5 & 162 & 598 & 52 & - & 652 & 934 & 1.1 \\
\hline UHSC & & 32.0 & 155 & 824 & 145 & - & 414 & 913 & 1.9 \\
\hline UHSC-FA10 & 0.16 & 32.0 & 155 & 727 & 145 & 97 & 403 & 889 & 1.8 \\
\hline UHSC-FA20 & & 32.0 & 155 & 630 & 145 & 194 & 392 & 865 & 1.8 \\
\hline
\end{tabular}

the degree of restraint through experiments on unrestrained shrinkage (autogenous and drying shrinkage tests). In addition, there is a limit on the evaluation of cracking possibility and cracking behavior through such experiments. Moreover, existing studies have mainly evaluated the shrinkage behavior of NSC and HSC, and there is little research on UHSC [5, 8 , 10].

Therefore, in this study, the shrinkage and cracking behavior were evaluated through unrestrained and restrained shrinkage experiments of HSC, VHSC (very-high-strength concrete), and UHSC with water-to-binder ratios (W/B) of $30 \%, 25 \%$, and $16 \%$, respectively [10]. Notably, in the case of UHSC of W/B 16\%, the shrinkage behaviors according to the substitution rate of fly ash were compared and evaluated, and the shrinkage amount affecting actual cracking was evaluated by comparing the restraint stress and drying shrinkage.

\section{Experimental Program}

2.1. Materials and Mix Proportions. In this study, free shrinkage behavior and restrained shrinkage cracking behavior of concrete of three strength levels and the effect of fly ash on shrinkage behavior of UHSC were investigated experimentally. Although compressive strength is not directly related to autogenous and drying shrinkage, to compare shrinkage behavior of UHSC to that of other HSC, mixes that have been used in the actual construction field were selected and represented as HSC and VHSC. UHSC with a waterto-binder ratio of 0.16 and design compressive strength of $120 \mathrm{MPa}$ was represented as UHSC. In the case of UHSC, to obtain designated compressive strength, silica fume with a replacement ratio of $15 \%$ was used for all UHSC mixes. The materials used for all concrete were Type I Portland cement, fine aggregate with specific gravity of 2.6 , and coarse aggregate with maximum aggregate size of $13 \mathrm{~mm}$ and specific gravity of 2.7. The details of mix proportions are presented in Table 1.

2.2. Tests for Mechanical Properties. For fresh concrete properties, slump flow, air content, and initial setting time were measured. Cylinder specimens of $100 \times 200 \mathrm{~mm}$ were produced for strength tests and elastic modulus test. For 24 hours after casting, they were cured in a curing room at $23 \pm 1^{\circ} \mathrm{C}$. After the molds were removed, they were stored in a water tank at $20^{\circ} \mathrm{C}$ up to the testing day. Compressive strength and splitting tensile tests were carried out in accordance with ASTM C39/C39 M-16 and ASTM C496/C496 M-11, respectively $[13,14]$. Elastic modulus tests were obtained from

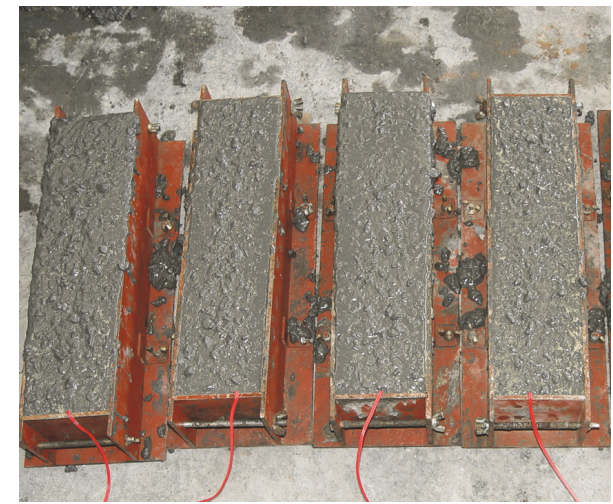

Figure 1: Drying shrinkage test specimens cast in molds.

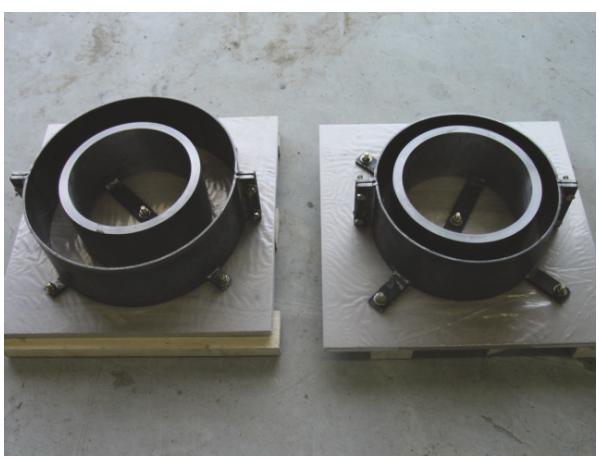

FIGURE 2: Ring test molds (left: $76 \mathrm{~mm}$ ring; right: $35 \mathrm{~mm}$ ring).

the stress-strain curve, which is measured by applying a uniaxial load to specimens with three strain gauges attached.

2.3. Drying Shrinkage Test. As shown in Figure 1, $100 \times$ $100 \times 400 \mathrm{~mm}$ specimens were used for the unrestrained drying shrinkage test. The test method was based on ASTM C157/C157 M-08 [15]. Shrinkage measurement was performed by using embedded gauges. After concrete placement, the molds were moved and stored in a curing room with a temperature of $23 \pm 1^{\circ} \mathrm{C}$ and humidity of $60 \pm 3 \%$. All shrinkage specimens were demolded 24 hours after casting.

2.4. Ring Test. The restrained shrinkage testing was conducted in accordance with ASTM C1581 [16]. The test method involves casting a concrete ring around a steel ring. Figures 2 and 3 show the molds and test setup, respectively. To investigate the effect of the concrete thickness on the degree 
TABLE 2: Properties of fresh and hardened concrete.

\begin{tabular}{lccccc}
\hline Mix & Slump flow $(\mathrm{mm})$ & Air content $(\%)$ & Initial setting $(\mathrm{hr})$ & $f_{\mathrm{cm}}(\mathrm{MPa})$ & 78.3 \\
\hline HSC & $470 / 480$ & 3.1 & 8.2 & 98.3 & $f_{\text {sp } 3 d}(\mathrm{MPa})$ \\
VHSC & $400 / 410$ & 3.6 & 10.1 & 125.7 & 4.1 \\
UHSC & $530 / 540$ & 1.8 & 12.0 & 123.5 & 5.4 \\
UHSC-FA10 & $520 / 510$ & 1.7 & 13.4 & 122.1 & - \\
UHSC-FA20 & $550 / 540$ & 1.8 & 15.1 & - \\
\hline
\end{tabular}

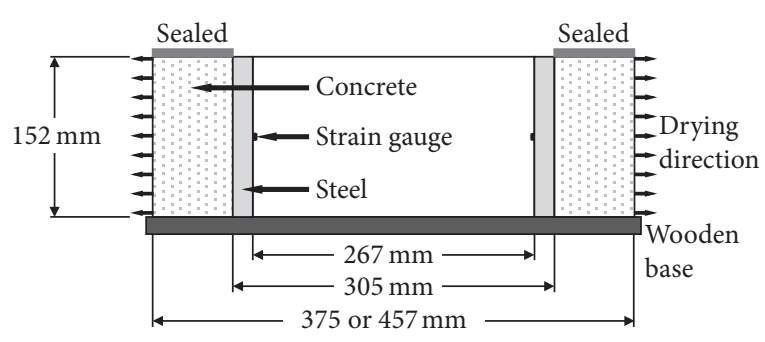

(a)

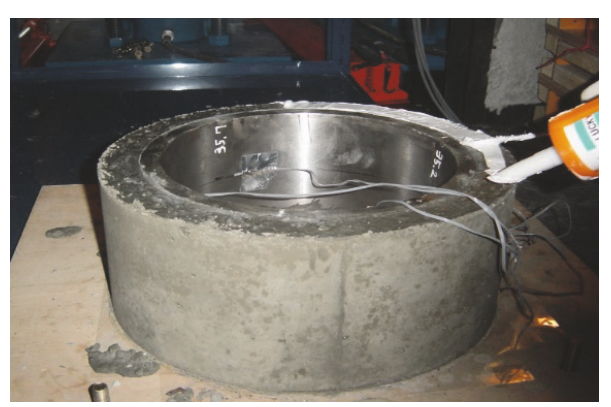

(b)

FIGURE 3: Ring test setup: (a) dimensions of ring test; (b) top sealing of ring specimen.

of restraint, the thickness of concrete ring specimens was varied by 76 and $35 \mathrm{~mm}$. Strain gauges were mounted on the inside of the steel ring to monitor the strain in the steel ring caused by the shrinkage of the concrete. Because of drying, concrete tends to shrink, but a steel ring prevents this. Thus, compressive stress is produced in the steel ring, which is balanced by tensile stress in the concrete. When cracking occurs in the concrete, the stress and strain in the steel are released.

The specimens were cured and measured in the following manner. Immediately after the specimens were fabricated, they were placed in an environment with a temperature of $23 \pm 1^{\circ} \mathrm{C}$ and humidity of $60 \pm 3 \%$. The specimens were then covered with wet burlap and a $0.15 \mathrm{~mm}$ polyethylene sheet and allowed to cure for 24 hours. After 24 hours, the outer ring mold was removed. The upper side of the concrete ring was sealed off using silicone-rubber sealer, so that drying would be allowed only from the outer circumferential surface, as shown in Figure 3. Steel strain measurements were conducted using a data logger, and each strain gauge was automatically recorded. The strain measurement was monitored from the time of casting until the concrete ring cracked.

\section{Test Results and Discussion}

3.1. Material Properties. Table 2 shows the properties of fresh concrete including workability and setting time. The initial setting time in UHSC was observed later than in HSC and VHSC, and incorporation of fly ash delays the initial setting of concrete. The higher the replacement ratio of fly ash, the later the initial setting time. Table 2 also shows the compressive strength at 28 days and splitting tensile strength at 3 days. The compressive strength of UHSC was approximately $47 \mathrm{MPa}$ and $27 \mathrm{MPa}$ larger than those of HSC and VHSC, respectively,

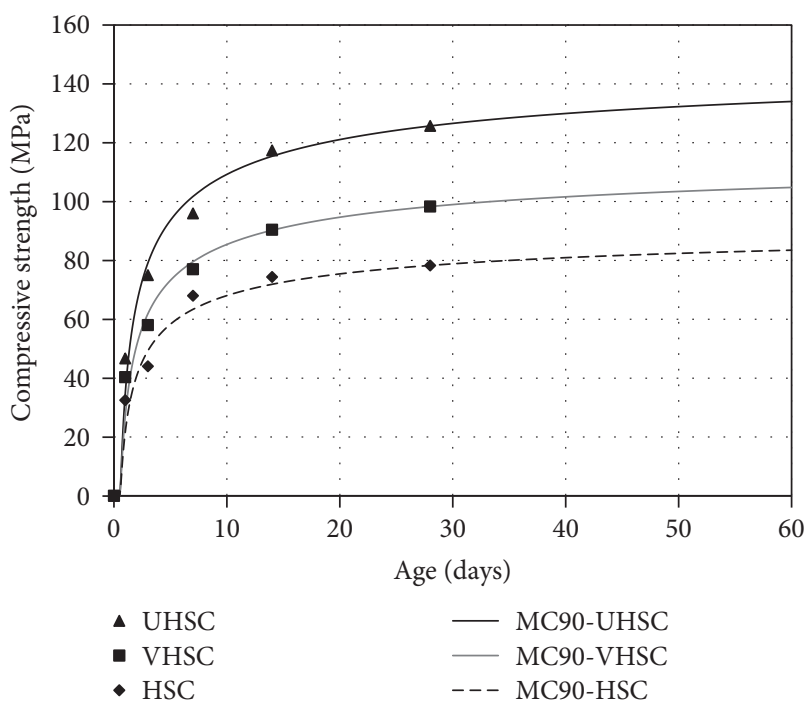

Figure 4: Comparison of compressive strengths of test results and CEB-FIP MC90 [11].

and there was no significant difference for splitting tensile strength between them. It is noted that compressive strength slightly decreased with increasing replacement ratio of fly ash, but the decrease is negligible, and it seems that fly ash does not inhibit long-term strength development. In addition, Figures 4 and 5 show the comparison between compressive strength and splitting tensile strength test results and predicted values. The prediction of compressive strength with time was in accordance with the formula given in CEB-FIP MC90 (see (1)), and the splitting tensile strength prediction formula was in accordance with ACI 363R (see (2)) as follows [11, 12]. When the ACI 363R equation is applied, $f_{\mathrm{cm}}(t)$ obtained from 


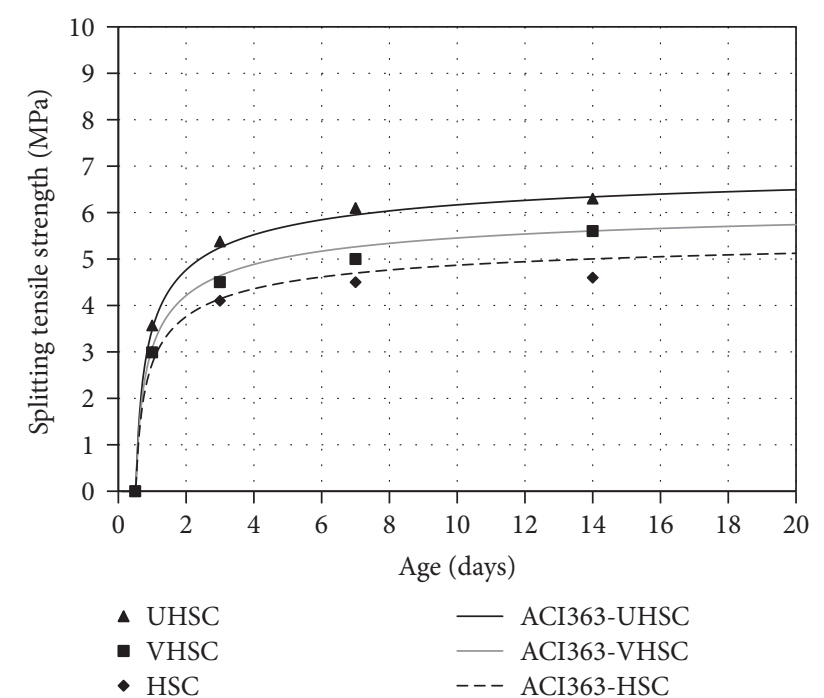

FIGURE 5: Comparison of splitting tensile strengths of test results and ACI 363R [12].

(1) is substituted into the value of $f_{c}^{\prime}$. Both compressive and splitting tensile strength test results were generally similar to the predicted value trends. It is noted that although the equation of ACI 363R is applied for concrete compressive strength of $83 \mathrm{MPa}$ or less, the calculated values for VHSC and UHSC with higher strength than $83 \mathrm{MPa}$ are very similar to the experimental values.

$$
f_{\mathrm{cm}}(t)=f_{\mathrm{cm}} \exp \left\{2.0\left[1-\left(\frac{28}{t}\right)^{1 / 2}\right]\right\},
$$

where $f_{\mathrm{cm}}$ is the mean compressive strength after 28 days and $t$ is the age of concrete (days).

$$
f_{\mathrm{sp}}=0.59 f_{c}^{\prime 0.5} \text { for } 21 \mathrm{MPa}<f_{c}^{\prime}<83 \mathrm{MPa} \text {, }
$$

where $f_{c}^{\prime}$ is the specified compressive strength.

3.2. Drying Shrinkage under Unrestrained State. Figure 6 shows the effect of $\mathrm{W} / \mathrm{B}$ on drying shrinkage under the unrestrained state. In this study, the drying shrinkage stands for the total drying shrinkage, which consists of autogenous shrinkage due to internal self-desiccation and pure drying shrinkage due to water loss to the outside environment. In the case of HSC and VHSC, the initial drying shrinkage of VHSC was relatively large, but, after 30 days, it became similar. This suggests that the initial shrinkage of HSC was small due to its low autogenous shrinkage, but the drying shrinkage increased due to the evaporation of free water over time. UHSC showed a dry shrinkage increase of approximately $250 \%$ at 60 days compared to VHSC. The reason for the great increase in the drying shrinkage of UHSC is mainly the very large autogenous shrinkage. For UHSC, the suction pressure due to self-desiccation increases with decreasing size of the internal pore, and the use of silica fume with high Blaine fineness enhances the void filling effect [17].

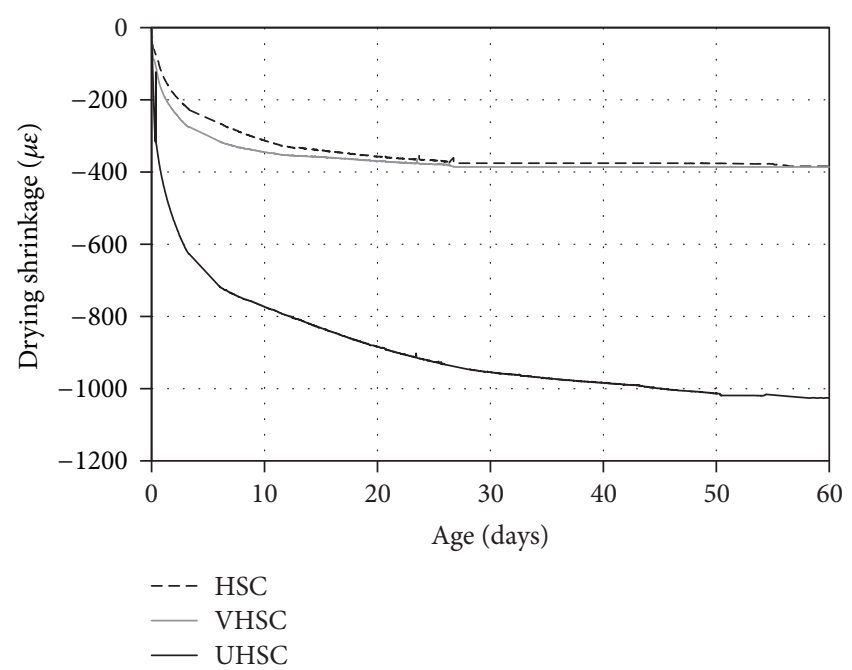

FIGURE 6: Drying shrinkage of concrete with different strength levels.

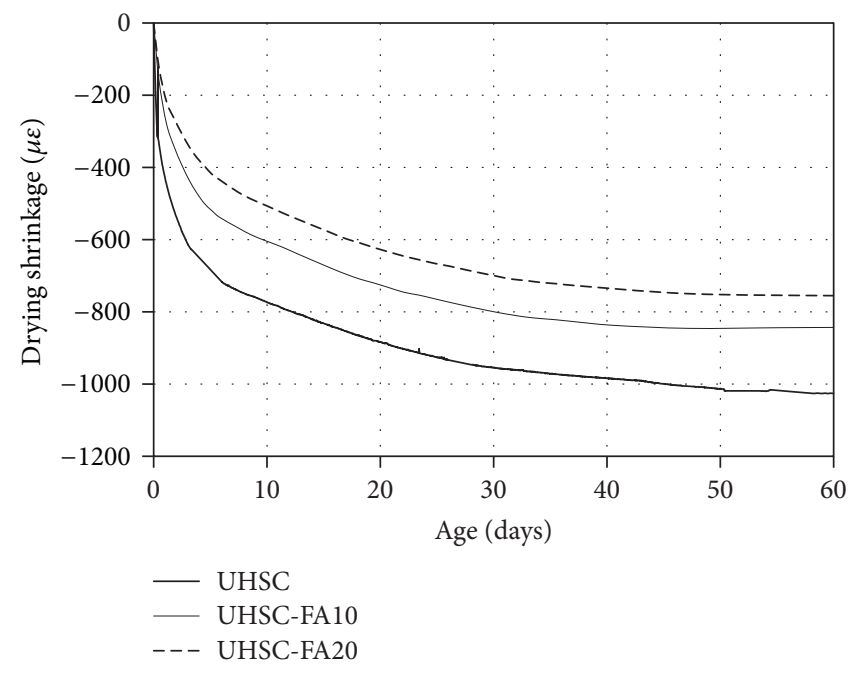

FIGURE 7: Drying shrinkage of UHSC with fly ash.

Figure 7 shows drying shrinkage according to fly ash content. Fly ash was found to reduce drying shrinkage. UHSC-FA10 and UHSC-FA20 showed a reduction of drying shrinkage by $15 \%$ and $23 \%$ at 60 days, respectively. The reason for the reduction of drying shrinkage by FA is considered to be that the evaporation of the free water was hindered by the fly ash filling the pores in the concrete.

3.3. Drying Shrinkage under Restrained State. Figure 8 shows the ring test specimen after cracks occurred. Figure 9 shows the strain of the inner steel ring according to concrete strength. UHSC demonstrates a much earlier cracking age and a much higher strain level than HSC and VHSC. In addition, a more abrupt cracking tendency was observed for the concrete with a higher strength level. The cracking ages of UHSC, VHSC, and HSC were 1.5, 2.8, and 3.5 days, respectively. The number of cracks was only one for all UHSC specimens, and there was no additional crack after the 


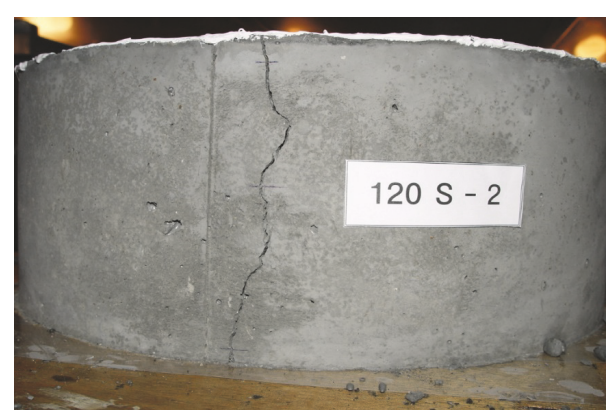

FIGURE 8: Cracking of ring specimen.

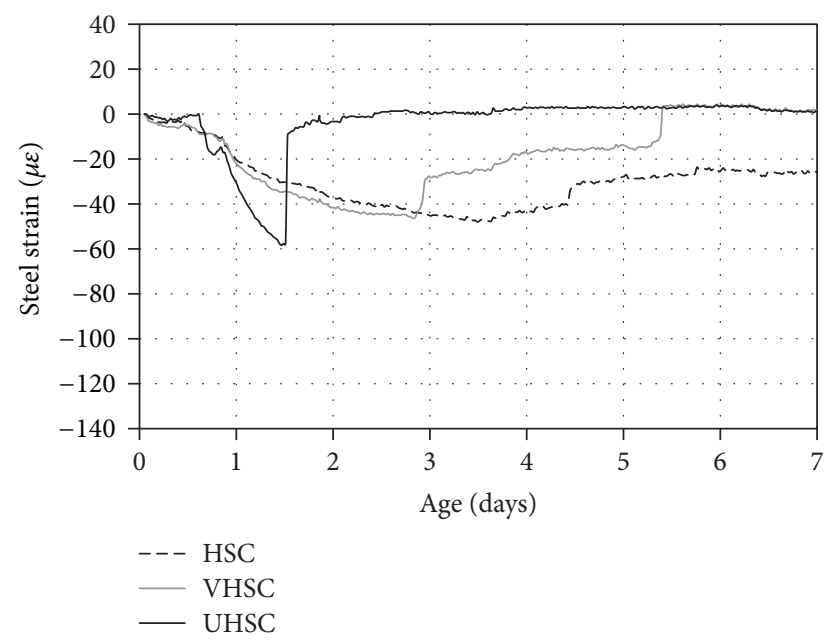

FIGURE 9: Average strain in the steel ring of HSC, VHSC, and UHSC (35 $\mathrm{mm}$ concrete ring).

first cracking. Although UHSC had higher tensile strength than HSC and VHSC at all ages, its shrinkage cracking performance was substantially poorer. This may be due to the higher free shrinkage, particularly at early ages, lower specific creep, higher modulus of elasticity, and lower aggregate interlock along cracked faces [4].

Figure 10 shows the results of ring tests of UHSC with fly ash. Previous study has shown that restrained shrinkage in HSC decreases with the replacement of fly ash, and the same tendency was observed in the test results [18]. At the $35 \mathrm{~mm}$ concrete ring test, for UHSC-FA10 and UHSC-FA20, the first crack was delayed by 2.4 and 19.2 hours, respectively, and the maximum restrained strain decreased by 4.0 and $6.7 \mu \varepsilon$ compared to UHSC. In the case of the $76 \mathrm{~mm}$ ring test, the same tendency as the $35 \mathrm{~mm}$ ring was shown. The crack time was delayed by 3.6 and 25.2 hours for UHSCFA10 and UHSC-FA20, and the maximum restrained strain was decreased by 9.3 and $7.3 \mu \varepsilon$, respectively. In the case of using fly ash, the phenomenon of retarding the initiation of shrinkage cracking under the restrained state can be explained by the relatively low drying shrinkage of UHSC with fly ash. In addition, from both $35 \mathrm{~mm}$ and $76 \mathrm{~mm}$ ring tests, it was commonly observed that the point at which the restrained strain increases steeply tends to be delayed because of the delayed hydration reaction due to the pozzolanic reaction of fly ash.

3.4. Restrained Stress and Splitting Tensile Strength. To obtain the equation that describes the state of stress in the concrete, the ring was separated into a concrete cylinder pressurized at the inner surface and a steel cylinder pressurized with an equal and opposite pressure at the outer surface as shown in Figure 11. The interface pressure can be determined from the steel ring using the steel properties, geometry of the steel ring, and strains that were measured at the inner radius of the steel using the electrical resistance strain gauges. This interface pressure can then be applied to the inside of the thick concrete ring to calculate the stresses using only the geometry of the concrete ring. These two steps can be combined into one expression for the maximum tensile stress that develops in the ring (the radial stress at the inner radius of the concrete ring). In this study, the maximum restrained stress was calculated from the following equation given by Miyazawa et al. [19]:

$$
\sigma(t)=\varepsilon_{s}(t) \cdot E_{s} t_{s} r_{1} \frac{r_{2}^{2}}{\left(r_{1}^{2}+1\right)\left(r_{2}^{2}-r_{1}^{2}\right)},
$$

where $\sigma(t)$ is the maximal stress applied in concrete, $\varepsilon_{s}(t)$ is the steel strain on the inner radius of the steel ring, $E_{s}$ is the elastic modulus of the steel ring, $t_{s}$ is the thickness of the steel ring, $r_{1}$ is the inner radius of the concrete ring, and $r_{2}$ is the outer radius of the concrete ring.

Figure 12 shows the restrained tensile stresses computed by (3) for the concrete with various strength levels. The dotted curves represent the splitting tensile strength of each specimen calculated by (2). It can be noticed that, at the same degree of restraint (i.e., the same ring thickness), the higher the strength levels, the closer the value to the splitting tensile strength at cracking. In the case of HSC and VHSC, the crack occurred at the $75 \sim 80 \%$ level of splitting tensile strength, whereas, in the case of UHSC, the restrained tensile stress at cracking reached the full tensile strength.

Figure 13 shows the restrained tensile stresses according to the thickness of the concrete ring. As the thickness of the concrete rings increased, the maximum restrained tensile stresses increased, and the cracking time of the concrete was delayed.

3.5. Relationship between Restrained Cracking and Unrestrained Drying Shrinkage. Figure 14 shows the drying shrinkage under unrestrained state measured from the bar specimen from the time of casting. There are two marks on each curve. The first mark (stick) indicates the free drying shrinkage strains at the age when the tensile stress in the concrete ring began to develop. For UHSC, UHSC-FA10, and UHSC-FA20, they are approximately 505, 54, and $45 \mu \varepsilon$ at the ages of $0.6,0.6$, and 0.7 days, respectively. The second mark (triangle) indicates the strains at the age of cracking in the ring test. For UHSC, UHSC-FA10, UHSC-FA20, they are approximately 762,321 , and $316 \mu \varepsilon$ at the ages of $1.5,1.6$, and 2.3 days, respectively. In the case of UHSC, although the absolute drying shrinkage was extremely large, the amount of drying shrinkage after the setting time was similar to that of 


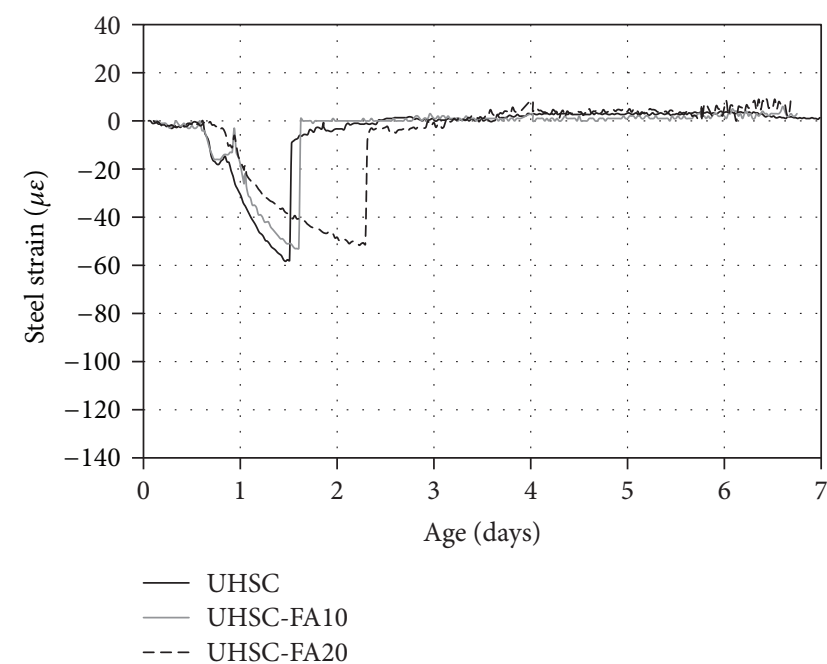

(a)

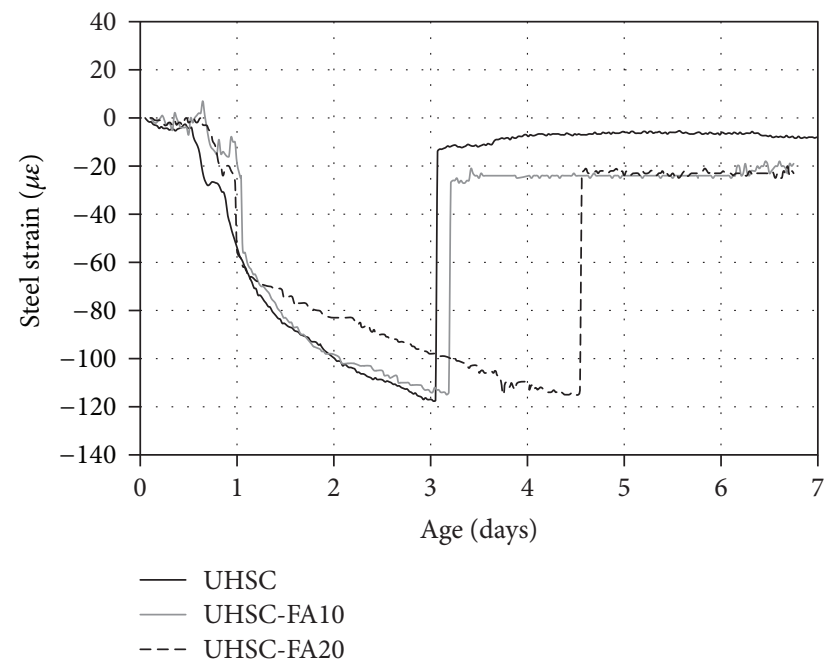

(b)

FIGURE 10: Average strain in the steel ring of UHSC with fly ash: (a) $35 \mathrm{~mm}$ concrete ring; (b) $76 \mathrm{~mm}$ concrete ring.

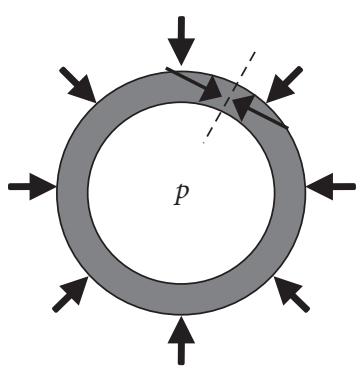

(a)

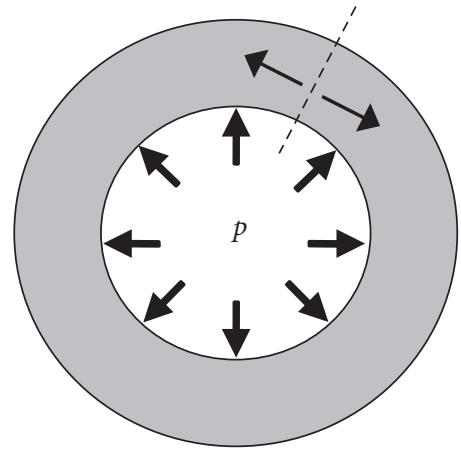

(b)

FIGURE 11: Stress transfer mechanism in ring test: (a) inner steel ring; (b) outer concrete ring.

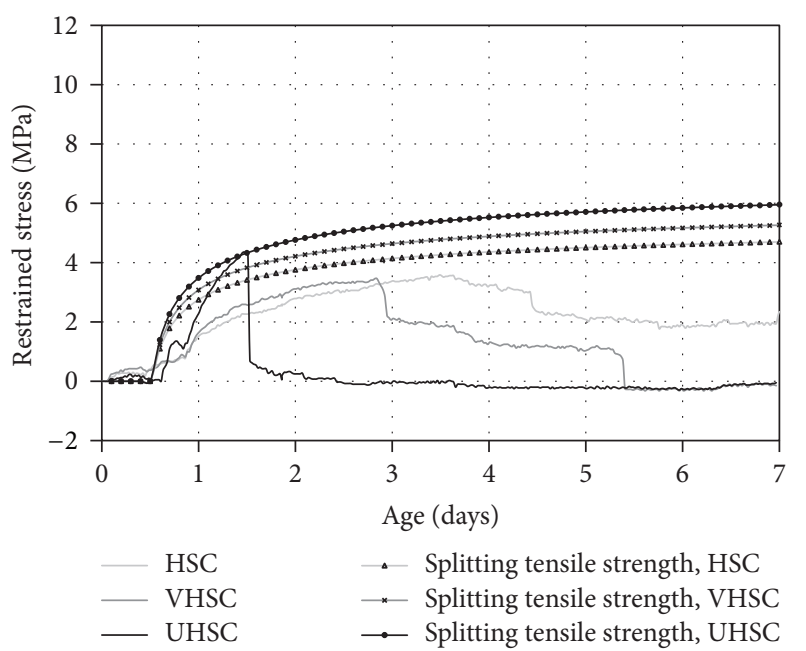

FIGURE 12: Maximum restrained stress of concrete ring with different strength levels.

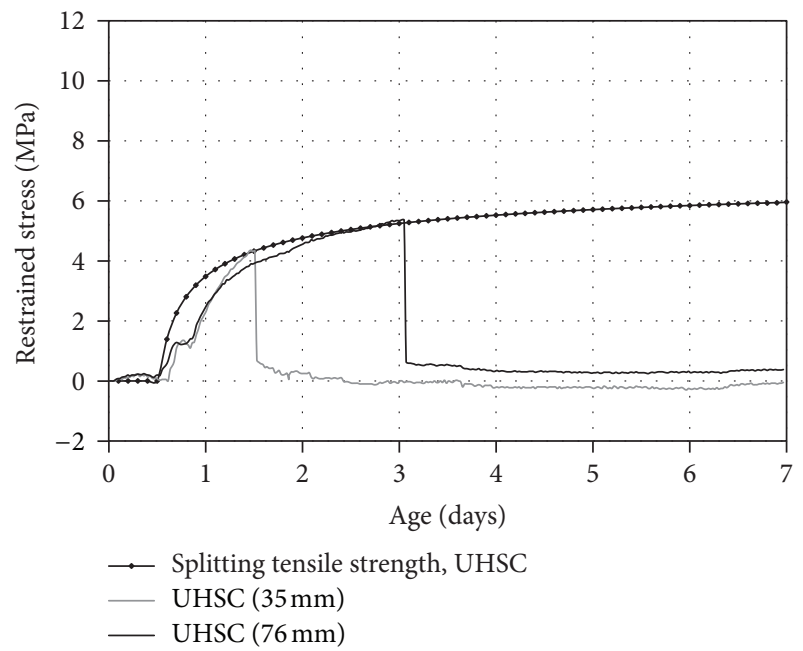

FIGURE 13: Maximum restrained stress of concrete ring with different thicknesses. 


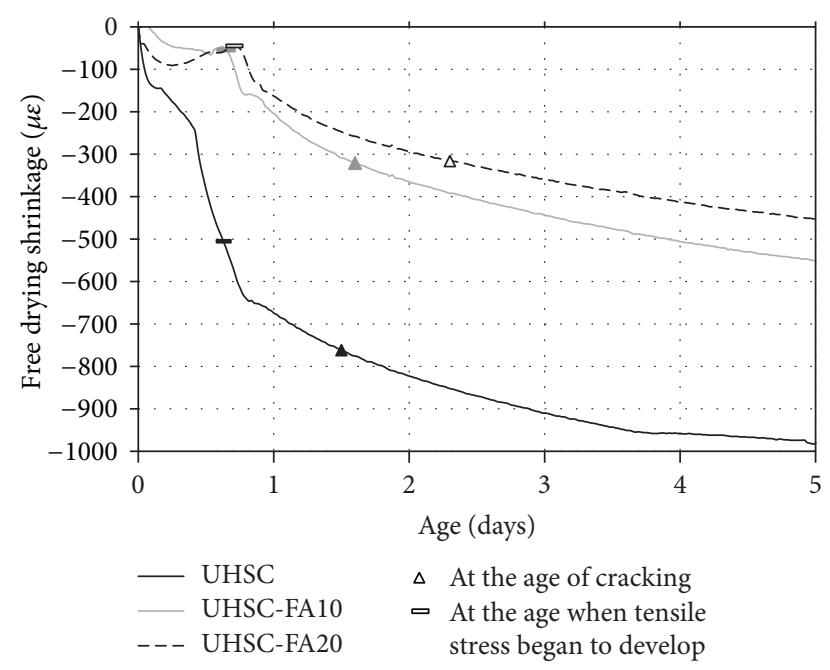

FIGURE 14: Relationship between restrained cracking and unrestrained drying shrinkage.

UHSC-FA10. Thus, the cracking ages of UHSC and UHSCFA10 were very similar. The tendency of the later cracking in UHSC-FA20 can be attributed to the slow shrinkage rate, especially after the setting time. It is noted that the difference in the drying shrinkage between the two points was similar for all three specimens, which was approximately $265 \mu \varepsilon$ on average. That is, the shrinkage from the setting to cracking time affected the restrained cracking. Therefore, to avoid early age cracking in UHSC, it would be effective to focus on controlling the shrinkage at an early age, especially after the initial setting time, which is approximately 0.6 days.

\section{Conclusions}

The following conclusions were drawn from the results of the restrained and unrestrained shrinkage tests of HSC, VHSC, and UHSC.

(1) UHSC of $120 \mathrm{MPa}$ was produced from W/B of $16 \%$ using general compounding material and coarse aggregate. The compressive strengths of UHSC were $47 \mathrm{MPa}$ and $27 \mathrm{MPa}$ higher than HSC and VHSC with W/B of $30 \%$ and $25 \%$, respectively, but there was no significant difference in the tensile strength. In addition, the compressive strength of UHSC at 28 days was somewhat small when fly ash was mixed, but it was not significant.

(2) The compressive and tensile strengths of the concrete according to CEB-FIP MC90 and ACI 363R showed good agreement with the experimental data.

(3) Drying shrinkage under the unrestrained state increased sharply when W/B decreased from $25 \%$ to $16 \%$, which is considered to be due to a very large autogenous shrinkage. However, as the amount of fly ash was increased, the amount of drying shrinkage was observed to decrease.

(4) As a result of the restrained shrinkage experiment, the cracks due to the restraint of the inner steel ring occurred earlier, and the cracking patterns were more brittle as $\mathrm{W} / \mathrm{B}$ decreased. Fly ash showed delayed occurrence of cracking, and tensile stress at cracking decreased slightly.

(5) The degree of restraint by the ring test decreased as the thickness of concrete increased. Fly ash also showed a tendency to decrease the restraint, and the effect was increased as the thickness of concrete increased. Therefore, it is considered that the increase of the concrete thickness and the use of fly ash under the restraint condition can effectively reduce the possibility of cracking of the concrete structure.

(6) Comparing the restrained cracks with the unrestrained drying shrinkage, it was found that restrained cracks occurred when the drying shrinkage after the initial setting occurred by more than a certain amount. Therefore, to control the initiation of the restrained cracks, it is necessary to make the occurrence of drying shrinkage slow and small after the concrete begins to set.

\section{Conflicts of Interest}

The authors declare that there are no conflicts of interest regarding the publication of this paper.

\section{Acknowledgments}

This research was supported by Railroad Technology Research Program funded by Ministry of Land, Infrastructure and Transport of Korean Government (Grant 16RTRPB067919-04).

\section{References}

[1] A. B. Hossain and J. Weiss, "The role of specimen geometry and boundary conditions on stress development and cracking in the restrained ring test," Cement and Concrete Research, vol. 36, no. 1, pp. 189-199, 2006.

[2] S. H. Kwon, R. P. Ferron, Y. Akkaya, and S. P. Shah, "Cracking of fiber-reinforced self-compacting concrete due to restrained shrinkage," International Journal of Concrete Structures and Materials, vol. 1, no. 1, pp. 3-9, 2007.

[3] K. Kovler and S. Zhutovsky, "Overview and future trends of shrinkage research," Materials and Structures, vol. 39, no. 293, pp. 827-847, 2006.

[4] K. Wiegrink, S. Marikunte, and S. P. Shah, "Shrinkage cracking of high-strength concrete," ACI Materials Journal, vol. 93, no. 5, pp. 409-415, 1996.

[5] K. M. Lee, H. K. Lee, S. H. Lee, and G. Y. Kim, "Autogenous shrinkage of concrete containing granulated blast-furnace slag," Cement and Concrete Research, vol. 36, no. 7, pp. 1279-1285, 2006.

[6] S.-I. Igarashi, A. Bentur, and K. Kovler, "Autogenous shrinkage and induced restraining stresses in high-strength concretes," Cement and Concrete Research, vol. 30, no. 11, pp. 1701-1707, 2000.

[7] S. G. Park, T. Noguchi, and M. H. Kim, "A study on the creep and autogenous shrinkage of high performance concrete with expansive additive and shrinkage reducing admixtures at early age," International Journal of Concrete Structures and Materials, vol. 18, no. 2E, pp. 73-77, 2006.

[8] P. Chindaprasirt, S. Homwuttiwong, and V. Sirivivatnanon, "Influence of fly ash fineness on strength, drying shrinkage 
and sulfate resistance of blended cement mortar," Cement and Concrete Research, vol. 34, no. 7, pp. 1087-1092, 2004.

[9] J. Weiss, W. Yang, and P. S. Surendra, "Influence of specimen size/geometry on shrinkage cracking of rings," Journal of Engineering Mechanics, vol. 126, no. 1, pp. 93-101, 2000.

[10] D. Y. Yoo, K. H. Min, J. M. Yang, and Y. S. Yoon, "Evaluation of shrinkage cracking characteristics and degree of restraint for ultra-high-strength Concrete," Journal of the Korea Concrete Institute, vol. 22, no. 5, pp. 641-650, 2010.

[11] CEB-FIP MC90, Comite euro-international du beton-federation international de la pre-contrainte (CEB-FIP), model code 90 for concrete structures, Thomas Telford Publishing, London, England, 1993.

[12] ACI Committee 363, Report on High-strength Concrete (363R-10, American Concrete Institute, MI, Farmington Hills, 2010.

[13] ASTM, "Standard test method for compressive strength of cylindrical concrete specimens," ASTM C39/C39M-16, ASTM International, West Conshohocken, Pa, USA.

[14] ASTM, "Standard test method for splitting tensile strength of cylindrical concrete specimens," ASTM C496/C496M-11, ASTM International, West Conshohocken, Pa, USA.

[15] ASTM, "Standard test method for length change of hardened hydraulic-cement mortar and concrete," ASTM C157/C157M08, ASTM International, West Conshohocken, Pa, USA, 2014.

[16] ASTM, "Standard test method for determining age at cracking and induced tensile stress characteristics of mortar and concrete under restrained shrinkage, ASTM International," ASTM C1581/C1581M-09a, ASTM International, West Conshohocken, Pa, USA, 2009.

[17] M. H. Zhang, C. T. Tam, and M. P. Leow, "Effect of water-tocementitious materials ratio and silica fume on the autogenous shrinkage of concrete," Cement and Concrete Research, vol. 33, no. 10, pp. 1687-1694, 2003.

[18] Z. Tao and Q. Weizu, "Tensile creep due to restraining stresses in high-strength concrete at early ages," Cement and Concrete Research, vol. 36, no. 3, pp. 584-591, 2006.

[19] S. Miyazawa, T. Kuroi, and E. Tazawa, "Autogenous shrinkage of cementitious materials at early ages," in Proceedings of the international workshop on control of cracking in early age concrete, pp. 203-212, Sendai, Japan, 2000. 

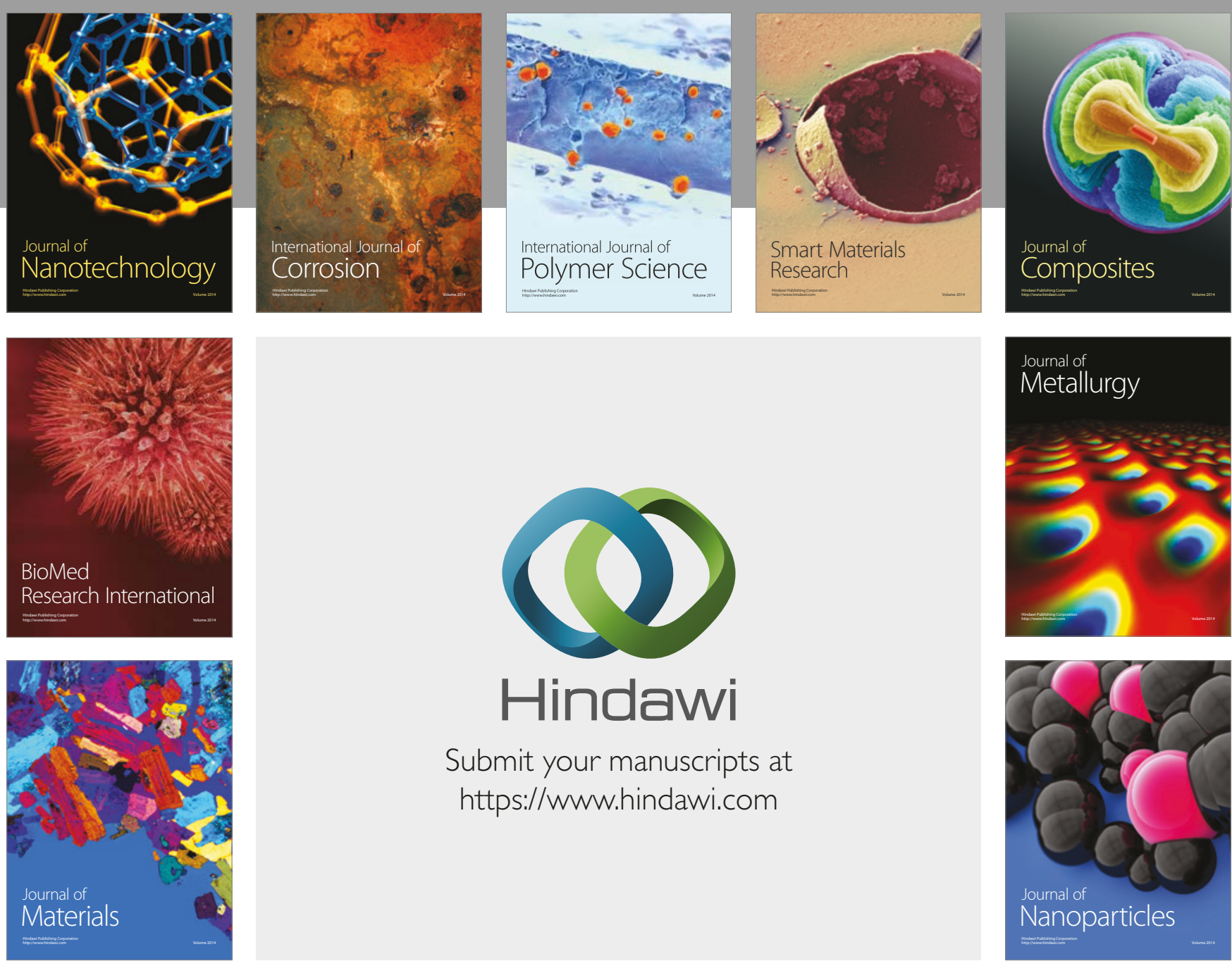

\section{Hindawi}

Submit your manuscripts at

https://www.hindawi.com
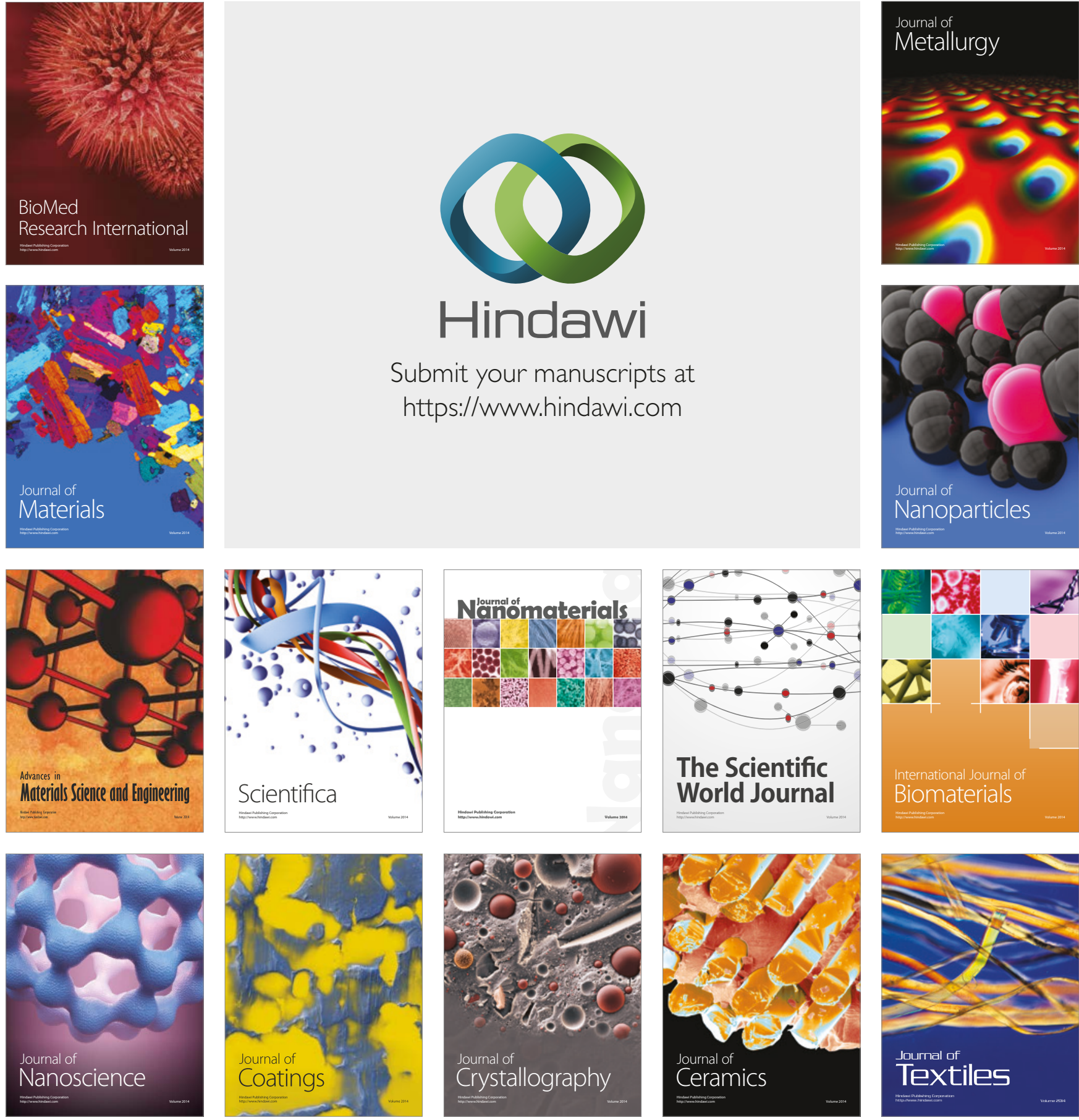

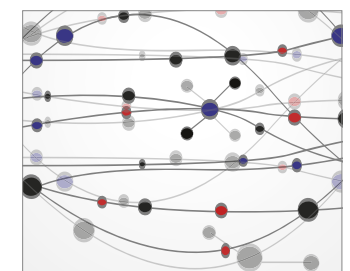

The Scientific World Journal
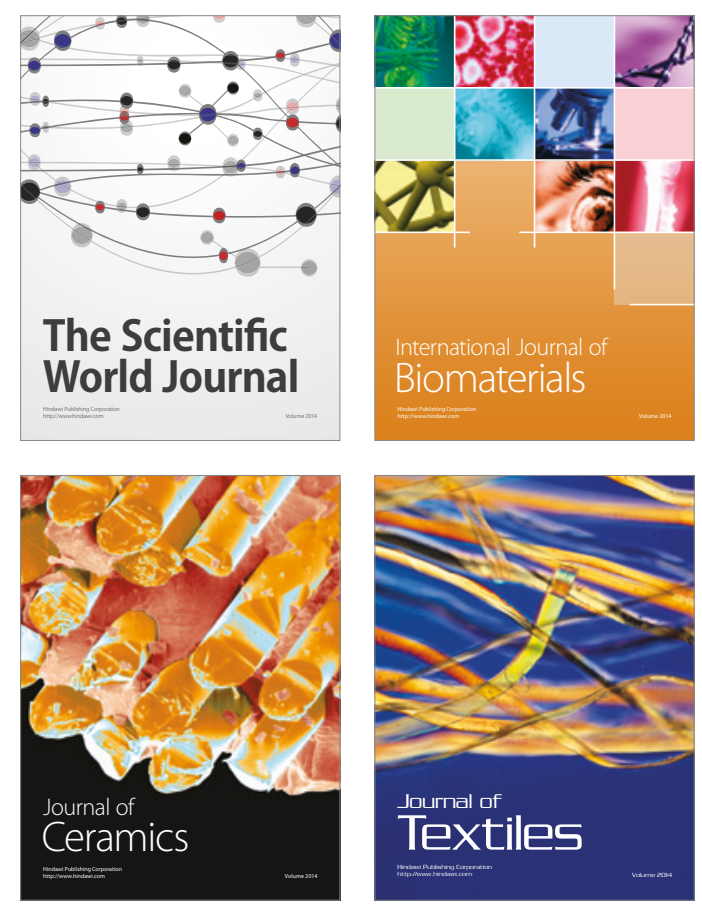